Revue des patrimoines

$41 \mid 2019$

Patrimoines gastronomiques. Définitions, typologies et enjeux de conservation

\title{
Le Réseau des Cités de la gastronomie, un outil innovant et fédérateur dédié à la mise en valeur des cultures culinaires
}

The 'Cités de la gastronomie' network, an innovatory and federating instrument for promoting culinary cultures

\section{Pierre Sanner}

\section{(2) OpenEdition}

Journals

Édition électronique

URL : http://journals.openedition.org/insitu/26888

DOI : 10.4000/insitu.26888

ISSN : 1630-7305

Éditeur

Ministère de la Culture

Référence électronique

Pierre Sanner, «Le Réseau des Cités de la gastronomie, un outil innovant et fédérateur dédié à la mise en valeur des cultures culinaires », In Situ [En ligne], 41 | 2019, mis en ligne le 15 décembre 2019, consulté le 19 décembre 2019. URL : http://journals.openedition.org/insitu/26888 ; DOI : 10.4000/ insitu. 26888

Ce document a été généré automatiquement le 19 décembre 2019.

In Situ Revues des patrimoines est mis à disposition selon les termes de la licence Creative Commons Attribution - Pas d'Utilisation Commerciale - Pas de Modification 4.0 International. 


\title{
Le Réseau des Cités de la gastronomie, un outil innovant et fédérateur dédié à la mise en valeur des cultures culinaires
}

\author{
The 'Cités de la gastronomie' network, an innovatory and federating instrument \\ for promoting culinary cultures
}

Pierre Sanner

1 Le 19 juin 2013, le gouvernement français annonçait la création d'un réseau d'équipements culturels à destination du grand public, consacrés à la promotion du «repas gastronomique des Français » et à la transmission de ses valeurs. À la veille de l'été, les ministres de la Culture et de l'Agriculture et de l'Agroalimentaire décidaient de créer non pas un musée de l'Alimentation mais de favoriser l'émergence de quatre Cités de la gastronomie. Ils affirmaient ainsi la volonté de la France de rapidement mettre en œuvre les engagements pris devant l'Unesco qui, en novembre 2010, avait inscrit sur la Liste représentative du patrimoine culturel immatériel de l'humanité «le repas gastronomique des Français ». Dès lors, le gouvernement et la Mission française du patrimoine et des cultures alimentaires (MFPCA) ont inventé un outil innovant et fédérateur des programmes des villes lauréates de Dijon, Lyon, Paris-Rungis et Tours. Le réseau des Cités de la gastronomie s'est ainsi s'affirmé dans le paysage culturel comme un instrument de coopération singulier consacré à l'une des plus fortes expressions de la culture et du patrimoine des Français.

2 À quelques semaines de l'inauguration de la Cité internationale de la gastronomie de Lyon au sein de l'imposant hôtel-Dieu, revenons sur la genèse du Réseau des Cités de la gastronomie, pour envisager les possibles développements de ce nouvel instrument à l'échelle de l'Europe. 


\section{La reconnaissance du repas gastronomique des Français}

3 En novembre 2010, pour la première fois de son histoire, l'organisation onusienne pour l'éducation, la science et la culture a permis à des pratiques et expressions culinaires de faire leur entrée au panthéon des plus belles créations du génie humain. En effet, lors de cette même session du $5^{\mathrm{e}}$ Comité intergouvernemental de sauvegarde du patrimoine culturel immatériel réuni à Nairobi (Kenya), non seulement « Le repas gastronomique des Français " est célébré comme un élément essentiel du patrimoine culturel de l'humanité mais également "La diète méditerranéenne », dossier présenté alors par quatre pays du pourtour méditerranéen, Espagne, Grèce, Italie et Maroc, et « La cuisine traditionnelle mexicaine, le paradigme de Michoacán, une culture communautaire, vivante et ancestrale». Aujourd'hui, près d'une vingtaine d'éléments issus des patrimoines alimentaires de différents pays ont été reconnus et inscrits sur les listes du patrimoine culturel immatériel; le café arabe, le keskek, le washoku, qui réunit les traditions culinaires des Japonais, la méthode géorgienne de vinification, la culture de la bière en Belgique, le pain plat lavash arménien, la préparation et le partage du kimchi, sous forme de deux dossiers, un pour chaque Corée, etc.

Le dossier français précise que le repas est « une pratique sociale coutumière destinée à célébrer les moments les plus importants de la vie des individus et des groupes ${ }^{1}$. C'est autrement dit l'expression du bien-être ensemble autour de la table, du plaisir du goût et d'une certaine harmonie entre l'être humain et les productions de la nature. Une pratique sociale qui se nourrit et s'exprime grâce à la passion et l'engagement de femmes et d'hommes qui contribuent chaque jour à faire de la gastronomie non seulement cette part essentielle de notre culture et de notre patrimoine mais également le plus bel ambassadeur d'un certain art de vivre à la française. Laurent Fabius, lorsqu'il était ministre des Affaires étrangères et du Développement international, n'a eu de cesse de rappeler que «la gastronomie, un repère identitaire pour les Français [...], occupe une place tout aussi importante dans l'image de la France à l'étranger» et de personnellement s'impliquer pour développer la «diplogastronomie $»^{2}$.

\section{Le rôle de la Mission française du patrimoine et des cultures alimentaires (MFPCA)}

5 Association régie par la loi de 1901, la MFPCA est l'organisme qui a porté le dossier de candidature de la France et obtenu en novembre 2010 l'inscription par l'Unesco du « repas gastronomique des Français » sur la Liste représentative du patrimoine culturel immatériel de l'humanité3. La Mission y est désignée comme

l'organisme spécifique et fédérateur qui doit assurer en lien avec l'État la veille et le suivi des mesures de sauvegarde et garantir la mise en œuvre des mesures appropriées aux termes et à l'esprit de la Convention pour la sauvegarde du patrimoine culturel immatériel. La Mission alertera l'État sur les risques éventuels d'utilisation dévoyée de l'inscription sur la liste de l'Unesco, tels que l'instrumentalisation ou la labellisation mercantile.

6 Le conseil d'administration de la Mission est composé de personnalités qualifiées, d'historiens, de géographes, de représentants du monde de la restauration et du monde 
agricole ainsi que de spécialistes des questions patrimoniales et gastronomiques. JeanRobert Pitte, géographe, secrétaire perpétuel de l'Académie des sciences morales et politiques, en est le président. La MFPCA, qui a conçu le principe de Cité de la gastronomie, assure la coordination des travaux et développements du Réseau des Cités de la gastronomie et accompagne chaque porteur dans l'élaboration de ses programmes éducatifs, scientifiques et culturels.

\section{La création du Réseau des Cités de la gastronomie, conséquence de la reconnaissance unesquienne}

7 Combien de touristes, chaque année, sont désireux de faire l'expérience de notre art de vivre, de goûter à la convivialité de nos tables, d'approcher la subtilité de nos terroirs agricoles et viticoles? Combien sont désireux d'embrasser, le temps d'un repas, une partie de la culture française ? Il est incontestable que l'inscription par l'Unesco, parce qu'elle nous honore autant qu'elle nous oblige, est une formidable chance de mieux mettre en valeur notre patrimoine culinaire. Il est indispensable de mieux le connaître pour mieux le partager. Ce sont là les simples et immenses défis que propose de relever chaque Cité de la gastronomie; promouvoir la richesse des pratiques culinaires, stimuler la vitalité des savoir-faire et développer des politiques de transmission pour les générations à venir. Le principe, s'il est original, n'en demeure pas moins relativement ancien. Il aura fallu attendre le milieu des années 1980 pour que la puissance publique et plus particulièrement le ministère de la Culture se préoccupe de gastronomie, une "culture populaire longtemps ignorée des élites de la République ${ }^{4}$. En avril 1984, le journaliste Jean Ferniot remet à Jack Lang et Henri Nallet, alors respectivement ministres de la Culture et de l'Agriculture, son Rapport sur la promotion des arts culinaires de la France, dont les recommandations, si elles n'ont pas toutes été suivies d'effet immédiat, ont néanmoins permis à la gastronomie, "cette passion française », d'obtenir un début de reconnaissance de la part des institutions culturelles. Dans ce même rapport et pour la première fois, il est préconisé la création d'un conservatoire des arts culinaires, dont le rédacteur précise qu'il devra s'inspirer du Centre Georges-Pompidou : «Il n'existe pas en France, patrie de la cuisine, des vins et des arts de la table, de véritable musée ou conservatoire qui réunisse les trésors de notre patrimoine. [...] Mais un musée n'est pas une nécropole. Il faut une institution vivante, un lieu de rencontre et d'animation, s'inspirant plutôt du Centre Pompidou que du Muséum d'histoire naturelle. ${ }^{5}$. Cette idée inspirera les porteurs du projet d'inscription, lorsqu'il s'agira de concevoir le plan de gestion ou mesures de sauvegarde du repas gastronomique des Français ; créer en France un « Beaubourg de la cuisine ».

8 Trente-cinq ans plus tard, notre pays est en passe de se doter - enfin - d'un outil original de mise en valeur de sa culture alimentaire. Ce concept, adapté aux exigences de l'époque, fut repris et développé sous le titre de "Cité de la gastronomie ». Malgré un contexte peu propice à l'investissement par l'État seul, l'idée fait son chemin, si bien que finalement le dossier mentionne que

la France s'engage à favoriser la création d'un équipement culturel pluridisciplinaire, à dimension nationale et internationale, [qui] contribuera à sensibiliser le public à l'histoire, aux fonctions et valeurs du repas, ainsi qu'à la vitalité de ses expérimentations en France et dans le monde. Cet équipement culturel se présente comme un espace vivant favorisant par des activités pédagogiques (ateliers, production éditoriale), artistiques et documentaires 
(expositions, rencontres, discussions), une meilleure connaissance de la pratique culturelle et sociale du repas gastronomique des Français, de ses rites et plus largement des traditions des repas des communautés partout dans le monde.

Le repas, entendu comme " une pratique sociale coutumière destinée à célébrer les moments les plus importants de la vie des individus et des groupes", est ainsi tout naturellement au cœur des Cités de la gastronomie. La mise en valeur du repas en particulier et du patrimoine gastronomique dans son ensemble constitue le socle commun du Réseau des Cités de la gastronomie. Les équipements culturels en cours de création s'attachent tous à promouvoir les métiers, les filières et les savoir-faire, à développer l'offre de formation professionnelle, à encourager la recherche et l'innovation, à stimuler l'éducation au goût et à sensibiliser le plus grand nombre aux plaisirs du bien manger ensemble. Il ne s'agit rien de moins que d'inventer des lieux de vie dédiés à la promotion et à la transmission des savoirs gastronomiques. Des équipements permettant de vérifier le fameux énoncé de Claude Levi-Strauss : «il ne suffit pas qu'un aliment soit bon à manger, encore faut-il qu'il soit bon à penser. » Des équipements susceptibles d'offrir en un même lieu l'ensemble des trésors gastronomiques de la France, de les faire aimer, de les comprendre, de les partager avec l'ensemble des Français, mais également avec les millions de touristes qui, chaque année, aspirent à découvrir un peu de la culture culinaire française. Il ne s'agit pas de " parcs à thème dédiés à la (bonne) bouffe ", mais bien plus de lieux stimulant les cinq sens qui, inspirés des marchés et des halles, offrent la possibilité d'un véritable " voyage en gastronomie ».

\section{Les quatre Cités de la gastronomie}

Quatre capitales régionales ont été retenues à l'issue d'un processus qui débuta, dès le lendemain de l'inscription, par le lancement d'un appel à manifestation d'intérêt pour la création d'une Cité de la gastronomie. Durant l'été 2012, la MFPCA instruisit les six dossiers de candidature qui lui avaient été adressés, avant de confier à une commission d'évaluation la responsabilité de mener les auditions des délégations de chaque ville 6 . Le 15 octobre 2012, les maires des villes concernées se présentèrent dans la salle AndréMalraux du ministère de la Culture pour exposer et défendre leur projet. Le prérapport souligne la qualité de trois puis quatre candidats - Dijon, Lyon, Paris-Rungis et Tours - mais insiste également sur le fait qu'aucun dossier ne répond en tous points au cahier des charges. La MFPCA, qui assure l'ingénierie du programme, écrit ainsi à l'attention des ministres: "Nous faisons le constat qu'aucune des candidatures ne s'impose pleinement comme le grand projet à visée internationale, "le Beaubourg de la cuisine”, que nous appelions de nos vœux et qui a été présenté dans le dossier validé par l'Unesco. » La décision de retenir quatre projets devait alors assez rapidement s'imposer. Le gouvernement encourage la création d'un réseau, qui fut officialisé le 19 juin 2013 lors d'une conférence de presse à l'hôtel de Villeroy, au ministère de l'Agriculture. La MFPCA, qui a conçu puis proposé la création de la cité de la gastronomie, a souligné, tout au long du processus d'évaluation et d'analyse des candidatures, la compatibilité des différents projets entre eux et surtout leur évidente complémentarité. C'est donc un dispositif de coopération et de mutualisation qui a été privilégié, afin d'illustrer la riche diversité du patrimoine gastronomique et de promouvoir la vitalité des cultures alimentaires. Un grand chantier s'est alors ouvert. 
11 Les acteurs ne se connaissaient pas et, pour la plupart, ignoraient tout ou presque des projets proposés par les autres collectivités. Il a donc fallu apprendre à se faire confiance pour partager des informations au-delà des effets de communication et, immédiatement, travailler à la définition des «pôles moteurs » qui permettront de caractériser les différentes cités. Des rendez-vous semestriels ont été organisés dans chacune des villes lauréates pour offrir un cadre de travail propice aux échanges vertueux.

Chacune des Cités de la gastronomie a ainsi construit et proposé un programme spécifique, qui lui confère aujourd'hui un rôle moteur dans des domaines d'intervention légitimes et pertinents. La mise en valeur d'axes de travail privilégiés mais non exclusifs a permis d'affirmer l'identité de chacune des cités au sein d'un réseau dynamique et structuré. Plusieurs « pôles moteurs » ont ainsi émergé.

13 La Cité de la gastronomie de Dijon, en liaison étroite avec l'Institut de la vigne et la chaire Unesco «Culture et traditions du vin », devait être le pôle moteur en matière de valorisation et de promotion de la culture de la vigne et du vin ${ }^{7}$. La Cité internationale de la gastronomie et du vin de Dijon s'appuie également sur l'inscription au Patrimoine mondial de l'Unesco des « climats de Bourgogne » (fig. 1, fig. 2).

Figure 1

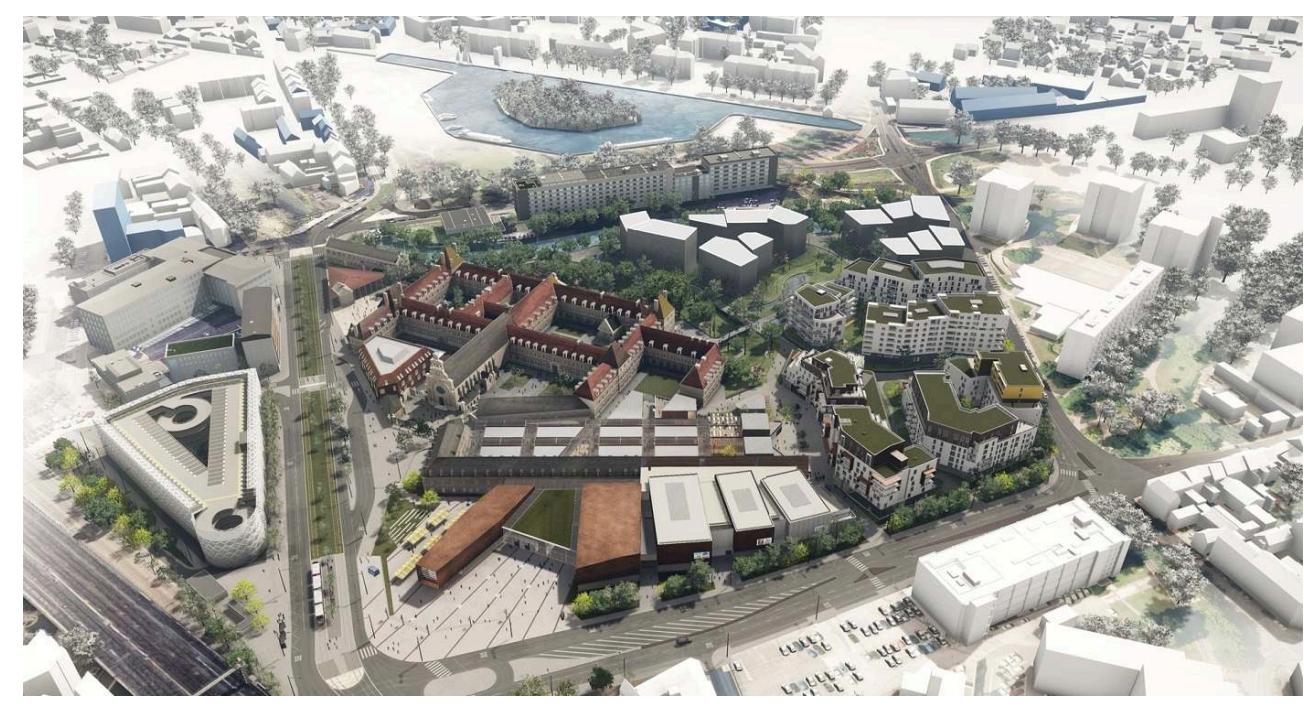

Vue aérienne de la future Cité de la gastronomie et du vin de Dijon.

(c) ENODO pour Eiffage Immobilier, 2019. 
Figure 2

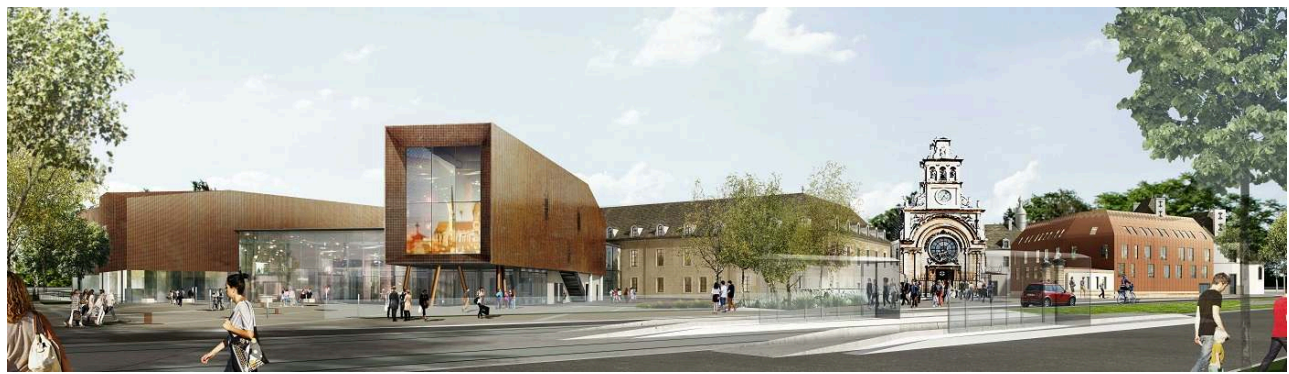

Parvis principal de la future Cité de la gastronomie et du vin de Dijon.

(c) AAAB pour Eiffage Immobilier, 2018.

14 La thématique associant alimentation et santé caractérise le pôle moteur animé par la Cité de la gastronomie au sein de l'hôtel-Dieu de Lyon $^{8}$ (fig. 3, fig. 4).

Figure 3

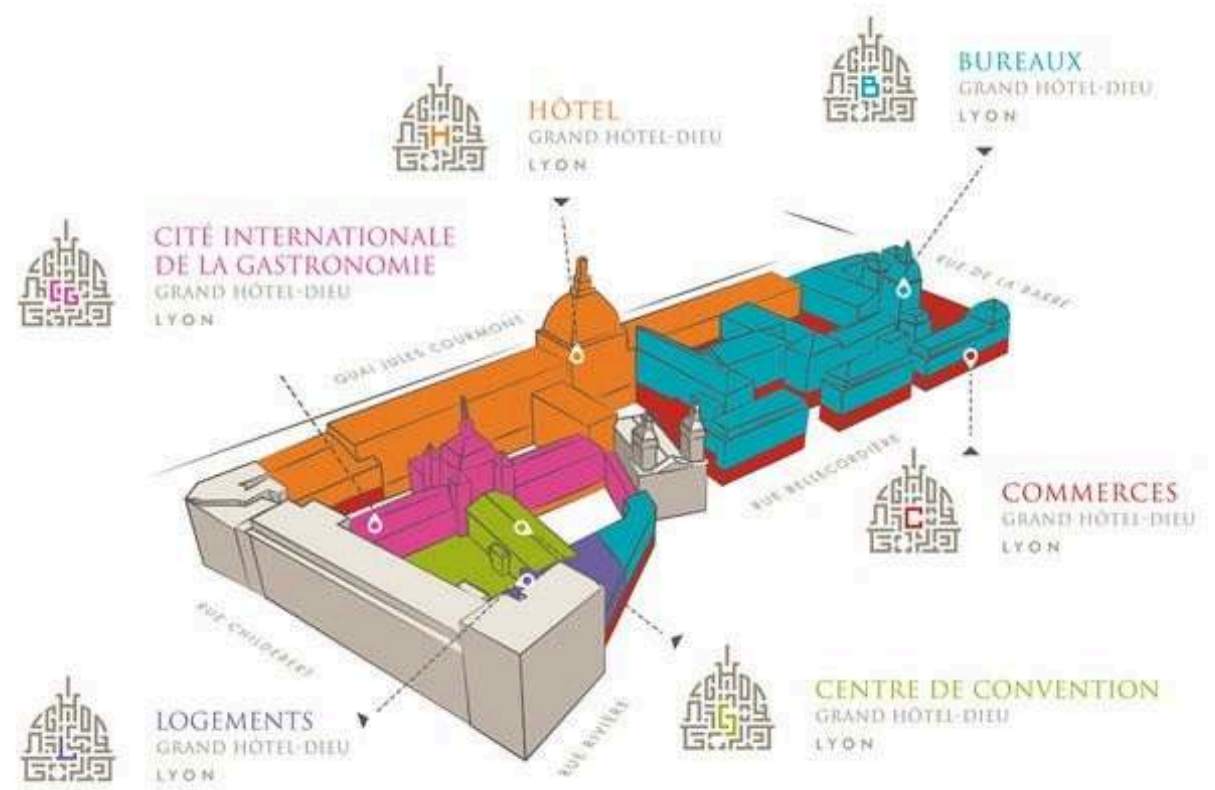

Plan de la Cité de la gastronomie de Lyon.

(c) Lyon Métropole, Eiffage, 2018. 
Figure 4

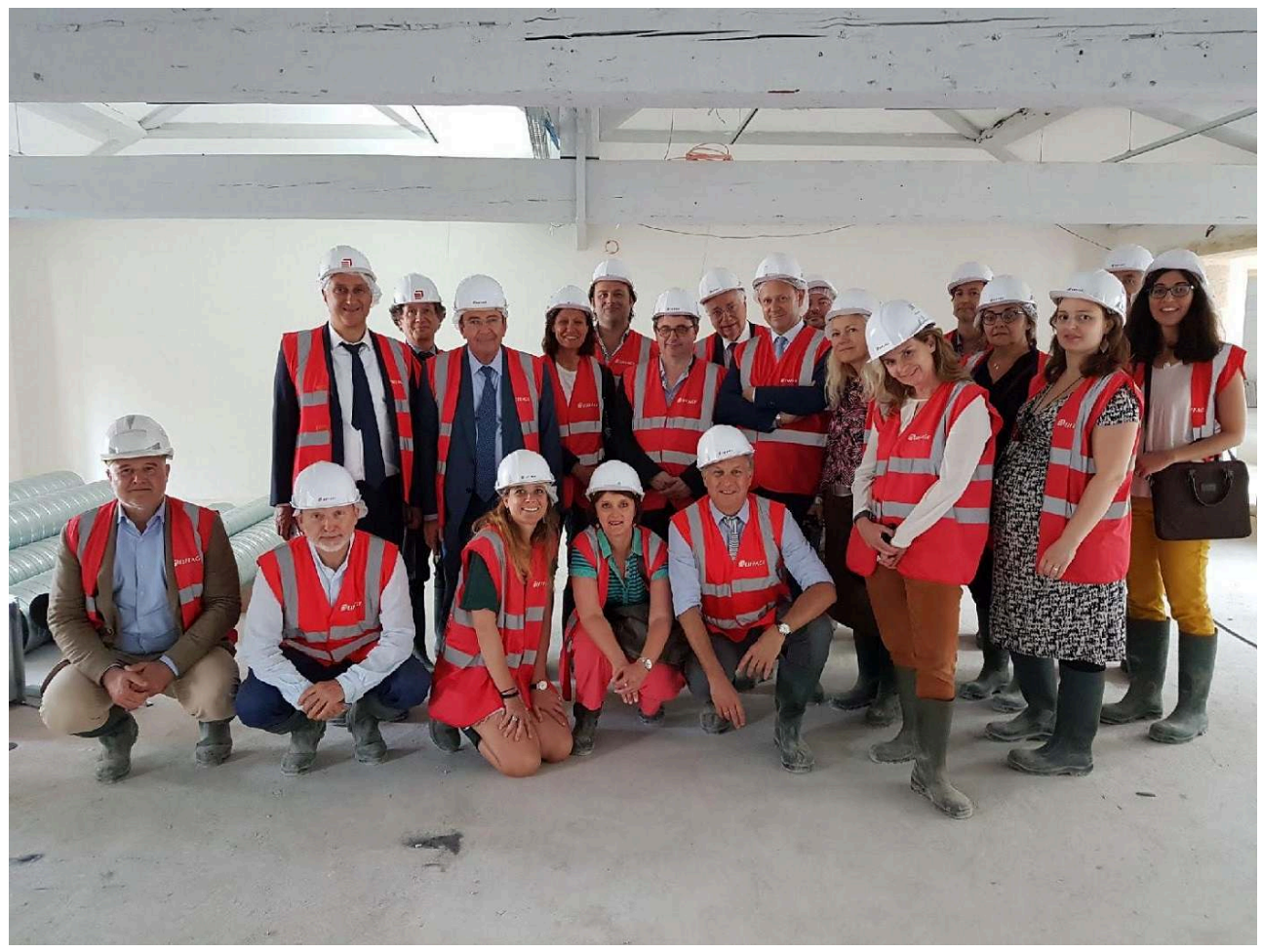

Vue de groupe sur le chantier de la Cité de la gastronomie de Lyon.

(c) MFPCA, juin 2018

Inscrite dans un territoire de grande diversité environnementale et culturelle, la Cité de la gastronomie de Paris-Rungis valorise une alimentation durable et une gastronomie responsable autour de la pratique sociale et festive du repas ${ }^{9}$. Cette cité est imaginée et conçue comme un ensemble culturel, où l'expérience pratique et sensorielle, pédagogique ou artistique, accompagne chaque temps, chaque espace (fig. 5). 


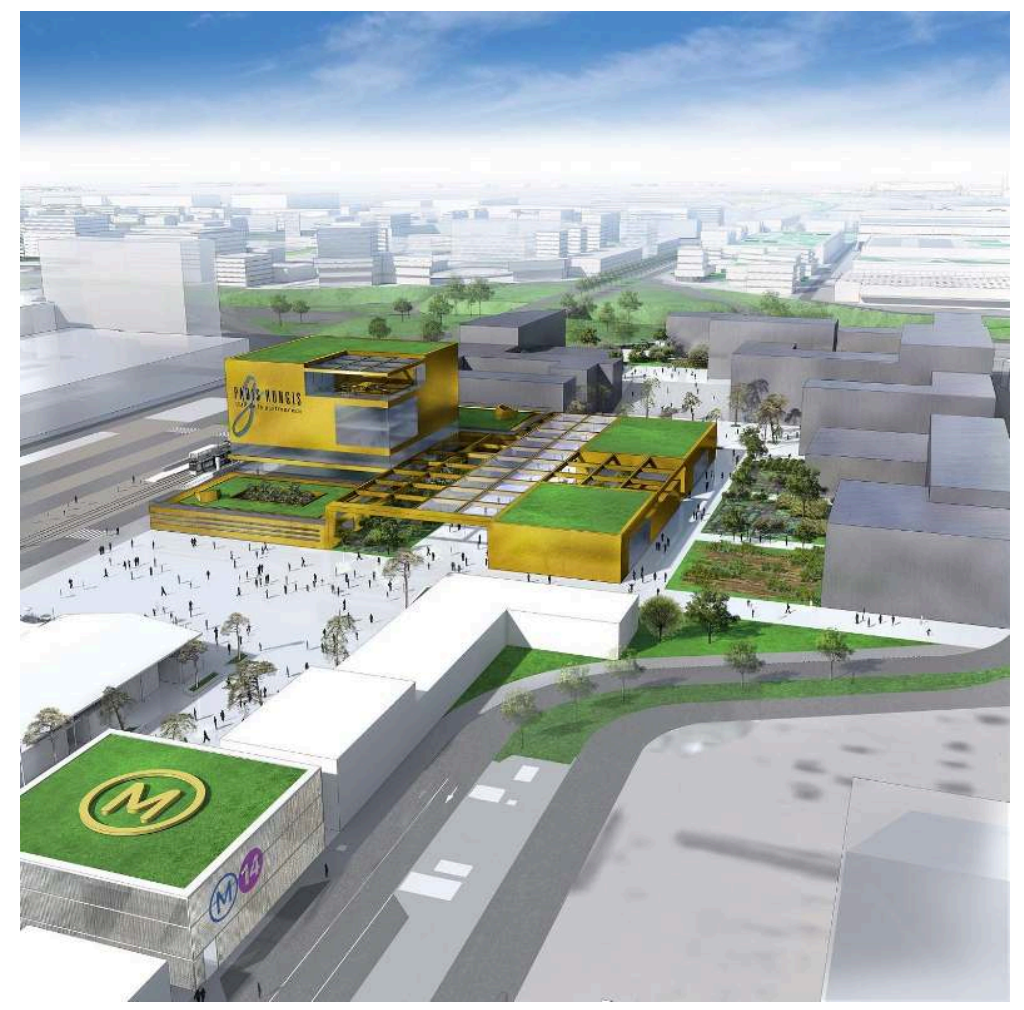

Projet de la Cité de la gastronomie de Paris Rungis.

(c) SMOCP-R, 2019

16 On peut également espérer que la cité de la région capitale aura à cœur de développer le volet international de façon spécifique, en affichant l'ambition d'un territoire fortement fréquenté par les touristes, à proximité d'un aéroport, Orly, qui draine plus de 27 millions de passagers. À proximité du marché international de Rungis, «le ventre de Paris» ne cesse de grandir, si bien qu'il est permis de parier sur le succès de la future « Halle des trésors gastronomiques ».

Le site de Tours anime d'ores et déjà le pôle moteur dans le domaine des sciences humaines et sociales, avec la constitution d'une Maison des cultures gastronomiques au sein de la villa Rabelais. La création d'un centre culturel et scientifique entièrement dédié à la gastronomie sous toutes ses formes s'appuie sur le travail mené inlassablement depuis sa création en 2001 par l'Institut européen d'histoire et des cultures de l'alimentation (IEHCA) ${ }^{10}$. La cité du Val-de-Loire tisse des liens étroits avec l'ensemble des acteurs de la région (universitaires, touristiques, culturels) pour faire pleinement résonner la double inscription à l'Unesco du périmètre ligérien (Patrimoine mondial) et du repas gastronomique des Français (Patrimoine culturel immatériel).

\section{Les actions du Réseau : calendrier et perspectives}

Les deux cycles de "Rendez-vous du Réseau " qui se sont tenus ont permis de structurer un dispositif souple et fédérateur. Le Réseau illustre et rend tangible la communauté de destin des Cités de la gastronomie, qui ont en partage la valorisation de la pratique sociale et festive du repas. 
19 Le réseau de ces cités encourage la mutualisation des programmes en respectant l'autonomie de gestion de chaque établissement. Il laisse entrevoir des partages d'expériences fructueux lorsque les quatre équipements seront effectivement opérationnels. En effet, à ce jour, le site de Tours, du fait de l'intense activité de l'IEHCA, permet d'entrevoir les possibles développements d'un centre de ressources sans équivalent et d'un espace de transmission et de formation du grand public extrêmement séduisant :

L'histoire, la géographie des produits et des recettes, les techniques de transformation et de conservation, les manières de tables ouvrent sur des pratiques culturelles d'une très grande richesse qu'il importe de mieux connaître, de protéger et de transmettre aux générations futures. Ce champ scientifique et culturel a en outre pour particularité d'être porteur d'enjeux sociétaux étendus ${ }^{11}$.

20 La Cité internationale de la gastronomie de Lyon prévoit d'ouvrir ses portes à l'automne 2019 au cœur de l'ancien hôtel-Dieu, avec notamment un parcours permanent et des expositions thématiques temporaires. À Dijon, la pose de la première pierre a définitivement lancé le chantier de la Cité internationale de la gastronomie et du vin, dont l'ouverture au public est prévue à la fin 2021. Le dynamisme des équipes de préfiguration et le travail conceptuel mené depuis six ans, notamment au sein du comité d'orientation stratégique, illustrent la volonté de mettre en œuvre, dans la capitale bourguignonne, un programme ambitieux de valorisation des cultures culinaires. L'inauguration de la Cité de la gastronomie aux abords du marché de Rungis devrait s'inscrire dans le même calendrier que la mise en circulation du prolongement de la ligne 14 du métro et l'accueil des prochains Jeux olympiques de 2024.

21 Après moins de six années d'activité, le Réseau des Cités de la gastronomie s'est affirmé dans le paysage culturel français, de telle sorte qu'il suscite - et c'est heureux - des demandes d'adhésion. À ce stade, cependant, la priorité n'est pas l'élargissement mais plutôt la consolidation d'une structure encore jeune. Il est indispensable d'assurer la mise en œuvre de chaque projet et d'accompagner les collectivités dans l'élaboration des programmes éducatifs, scientifiques et culturels conformément aux engagements pris vis-à-vis de l'Unesco.

22 Ainsi, en s'appuyant sur les axes de travail développés, souvent de longue date, par chacun des sites, le réseau permet de renforcer les actions des Cités de la gastronomie et de garantir le bon respect de l'intérêt général. La force du Réseau doit se vérifier également dans sa capacité à initier des projets communs en matière de découverte culturelle et d'expérience gustative. Les Cités, véritables vitrines de l'art de vivre à la française, s'inscrivent pleinement au cœur de leur territoire pour en renforcer l'attractivité au moyen de plateforme d'information et d'orientation sur les myriades d'activités qui composent le secteur de la gastronomie (fêtes et festivals, restaurants, œnotourisme, dégustations, routes gastronomiques et itinérance au cœur des terroirs, lieux du patrimoine et d'expression du savoir-faire autant que du savoir-être...).

23 Le Réseau des Cités de la gastronomie a contribué à renforcer les stratégies de développement de chaque projet et pourra, à l'avenir, prendre une part plus grande dans les politiques d'action culturelle (ou de préfiguration) des différentes Cités. Ainsi, les prochains mois sont susceptibles d'inaugurer une phase de co-production active d'événements, de manifestations ou d'expositions itinérantes et, dans le même temps, d'esquisser les contours d'un réseau qui pourrait s'exprimer à une plus grande échelle. Une source d'inspiration peut être le Réseau des villes créatives de l'Unesco ${ }^{12}$, qui 
propose de renforcer les coopérations dans différents domaines, dont la gastronomie, entre différentes villes ainsi consacrées: Parme (Italie), Burgos (Espagne), Bergen (Norvège) ou Ostersund (Suède), en Europe, mais également Zahlé (Liban), Florianopolis (Brésil), Popayan (Colombie), Chengdu (Chine) ou Jeonju (Corée)... La MFPCA étudie la possibilité de rejoindre ce réseau en proposant non pas une mais quatre villes françaises, celles-là même qui ensemble, composent le Réseau des Cités de la gastronomie.

\section{Conclusion}

À l'échelle européenne, il semble déterminant de prendre en compte la résolution du Parlement européen, adoptée à la quasi-unanimité de ses membres le 12 mars 2014, qui porte sur le patrimoine gastronomique européen et sur ses aspects culturels et éducatifs ${ }^{13}$. Elle rappelle opportunément, en effet, que la gastronomie est «l'une des manifestations culturelles les plus importantes de l'être humain » et n'omet pas de souligner que «la gastronomie est un outil permettant de stimuler la croissance et l'emploi dans de nombreux secteurs économiques, tels que la restauration, le tourisme, l'industrie agroalimentaire et la recherche». Par ce texte, le Parlement européen encourage chacun des vingt-huit pays membres de l'Union européenne à mettre en œuvre des politiques d'identification, de promotion et de valorisation des nombreux secteurs qui composent la gastronomie. Il serait impardonnable que cette résolution qui date déjà d'il y a cinq ans - reste lettre morte. La France pourrait parfaitement proposer avec d'autres États de lancer une grande campagne de recensement du patrimoine gastronomique de l'Europe. Notre pays peut faire valoir à cet égard une réelle expertise, illustrée notamment par les inventaires régionaux du patrimoine culinaire de la France, produits du terroir et recettes traditionnelles - une recommandation du rapport Ferniot mise en œuvre par le Conseil national des arts culinaires $^{14}-$, et aujourd'hui par l'Inventaire national du patrimoine culturel immatériel, dans sa dimension de pratiques alimentaires, culinaires et gastronomiques. Dans cet esprit, le Réseau des Cités de la gastronomie entend également s'emparer de certaines des préconisations. La MFPCA souhaite ainsi accompagner l'IEHCA dans sa volonté de faire de la Maison des cultures gastronomiques à Tours l'Observatoire européen de la gastronomie que le Parlement européen a appelé de ses vœux. Des nouveaux chantiers s'ouvrent...

\section{NOTES}

1. - Accessible en ligne: https://ich.unesco.org/fr/RL/le-repas-gastronomique-desfrancais-00437 [consulté le 04/08/2019].

2. - Le Repas gastronomique des Français. Paris : Gallimard, 2015, p. 7.

3. - Voir le site : https://repasgastronomiqueunesco.fr [consulté le 04/08/2019].

4. - CHEVRIER, Francis. Notre gastronomie est une culture. Paris : François Bourin, 2011.

5. - FERNIOT, Jean. Rapport aux Ministres sur la promotion des arts culinaires. Paris : avril 1985. 
6. - Voir le processus, accessible en ligne sur : https://repasgastronomiqueunesco.fr/les-cites-dela-gastronomie/le-reseau/ [consulté le 04/08/2019].

7. - Voir le site de la Cité: https://www.dijon.fr/Dijon-Capitale/Gastronomie-vin/La-Citeinternationale-de-la-gastronomie-et-du-vin [consulté le 04/08/2019].

8. - Voir le site de la Cité : https://www.grandlyon.com/projets/cite-internationalegastronomie.html [consulté le 04/08/2019]. Voir aussi dans ce numéro LIVOLSI, Solenne. «L'exposition permanente de la Cité Internationale de la Gastronomie de Lyon: expographie d'un patrimoine immatériel », In Situ [En ligne], 41|2019, mis en ligne le 09 décembre 2019, consulté le 15 décembre 2019. URL : http://journals.openedition.org/insitu/26048.

9. - Voir le site de la Cité : https://citegastronomie-parisrungis.com/ [consulté le 04/08/2019].

10. - Voir le site : http://iehca.eu/ [consulté le 04/08/2019].

11. - Note d'intention, Rendez-vous du Réseau, Tours, 24 mai 2019.

12. - Voir le site en ligne : https://fr.unesco.org/creative-cities/creative-cities-map [consulté le 04/08/2019].

13. - Accessible en ligne: http://www.europarl.europa.eu/sides/getDoc.do?pubRef=-//EP// TEXT+TA+P7-TA-2014-0211+0+DOC+XML+V0//FR [consulté le 04/08/2019].

14. - Le dernier volume, consacré à la région Centre, a été publié aux éditions Albin Michel en 2012.

\section{RÉSUMÉS}

La création des Cités de la gastronomie, mesure phare du plan de gestion qui découle de l'inscription par l'Unesco, en novembre 2010, du « repas gastronomique des Français » sur la Liste représentative du patrimoine culturel immatériel de l'humanité, tend à s'affirmer dans le paysage des équipements culturels français. Les quatre projets - Dijon, Lyon, Paris-Rungis et Tours - ont été regroupés pour constituer le Réseau des Cités de la gastronomie. Cette structure originale et souple se révèle un outil innovant et fédérateur d'équipements dédiés à la mise en valeur du « repas gastronomique des Français » et plus largement, des cultures culinaires dans leur ensemble. Cette contribution revient sur le processus de création du Réseau des Cités de la gastronomie et en esquisse les possibles développements à l'échelle de l'Europe.

The creation of 'Cités de la gastronomie', cultural centres for the gastronomical heritage, is one of the main measures in the management plan that followed UNESCO's inscription on its representative list of intangible cultural heritage of the 'Gastronomic meal of the French', in November 2010. These Cités are gradually occupying a significant place in the general landscape of French cultural facilities. The four projects, at Dijon, Lyon, Paris-Rungis and Tours, have joined forces to create a special network. It is an original and flexible structure which turns out to be an innovatory and federating tool for the various institutions dedicated to the promotion of the 'Gastronomic meal of the French' and to culinary cultures, more generally. Our article gives an account of how this network was set up and sketches out its possible development at a European level. 
INDEX

Keywords : gastronomy, network, “cités”, intangible cultural heritage, heritage, intangible, safeguard, culinary cultures, Unesco, Paris, Rungis, Tours, Dijon, Lyon, Hôtel Dieu

Mots-clés : gastronomie, réseau, cité, patrimoine culturel immatériel (PCI), patrimoine, immatériel, sauvegarde, cultures culinaires, Unesco, iehca, Paris, Rungis, Tours, Dijon, Lyon, Hôtel Dieu

\section{AUTEUR \\ PIERRE SANNER}

Directeur de la Mission française du patrimoine et des cultures alimentaires (MFPCA), Président de « France PCI ", association qui réunit les éléments français inscrits sur les listes de sauvegarde du Patrimoine culturel immatériel de l'UNESCO pierre.sanner@mf-pca.fr 